\title{
PENERAPAN METODE AHP SEBAGAI PENUNJANG KEPUTUSAN PENERIMAAN KARYAWAN PADA PT. ARKONIN
}

\author{
Warosatul Ilmiyah'1, Frieyadie ${ }^{2}$, Frisma Handayanna ${ }^{3}$ \\ 1,2 Program Studi Sistem Informasi \\ STMIK Nusa Mandiri Jakarta \\ www.nusamandiri.ac.id \\ wilmiyah@bsm.co.id,frieyadie@nusamandiri.ac.id \\ Program Studi Teknik Informatika \\ STMIK Nusa Mandiri Jakarta \\ www.nusamandiri.ac.id \\ frisma.fha@nusamandiri.ac.id
}

\begin{abstract}
Abstrak
Perusahaan membuka lowongan pekerjaan, maka dalam waktu yang singkat biasanya akan dibanjiri oleh berkas-berkas dari para pencari kerja. Permasalahannya adalah terkadang perusahaan mengalami kesulitan dalam menyeleksi pelamar pekerjaan, sehingga pelamar yang sebenarnya tidak memenuhi kriteria atau kebutuhan diikutkan dalam proses wawancara, atau bahkan diterima bekerja di perusahaan tersebut. Akibatnya perusahaan akan memiliki tenaga kerja yang sebenarnya tidak sesuai dengan kebutuhan perusahaan. Penelitian ini memiliki tujuan untuk memudahkan menentukan pelamar mana yang benar-benar berkompeten dan layak menjadi karyawan untuk posisi tertentu di sebuah perusahaan dan memudahkan penempatan karyawan pada divisi yang tersedia sesuai dengan keahlian yang dimiliki dan kebutuhan. Metode yang digunakan untuk menjawab permasalahan yang dihadapi dengan metode AHP. Hasil AHP yang diperoleh dari kuesioner dengan 3 responden yang memberikan jawabannya dihitung dan didapat hasil akhir bahwa calon karyawan B unggul (52,3\%) berbanding dengan calon karyawan A $(37,2 \%)$ dan calon karyawan C (10,5\%).
\end{abstract}

Kata kunci: Penerimaan Karyawan, Penunjang Keputusan, Metode AHP

\begin{abstract}
Companies open job vacancies, so in a short time usually will be flooded with files from job seekers. The problem is sometimes companies have difficulty in selecting job applicants, so applicants who actually do not meet the criteria or needs are included in the interview process, or even accepted to work at the company. As a result the company will have a workforce that is actually not in accordance with company needs. This study aims to make it easier to determine which applicants are truly competent and fit to be employees for certain positions in a company and facilitate the placement of employees in divisions that are available according to their expertise and needs. The method used to answer the problems faced by the AHP method. AHP results obtained from a questionnaire with 3 respondents who gave their answers were calculated and the final results obtained that prospective employee $B$ was superior (52.3\%) compared to prospective employee $A$ (37.2\%) and prospective employee $C(10.5 \%)$.
\end{abstract}

Keywords: Employee Acceptance, Decision Support, AHP Method

\section{PENDAHULUAN}

Saat suatu perusahaan membuka lowongan pekerjaan, maka dalam waktu yang singkat biasanya akan dibanjiri oleh berkas-berkas dari para pencari kerja. Permasalahannya adalah terkadang perusahaan mengalami kesulitan dalam menyeleksi pelamar (Frieyadie, 2017) pekerjaan, sehingga pelamar yang sebenarnya tidak memenuhi kriteria (Herdiyanti \& Widianti, 2013) atau kebutuhan diikutkan dalam proses wawancara, atau bahkan diterima bekerja di perusahaan tersebut. Akibatnya perusahaan akan memiliki tenaga kerja yang sebenarnya tidak sesuai dengan kebutuhan perusahaan (Hadi, Purnama, \& Rahman, 2018). Hal ini secara tidak langsung dapat menghambat produktivitas perusahaan itu sendiri. Dalam pelaksanaannya, perusahaan tentunya membutuhkan banyak karyawan dengan berbagai macam keahlian dan tingkat pendidikan. Untuk berbagai posisi jabatan 
dan jenjang diperlukan berbagai kualifikasi personil.

Proses seleksi adalah untuk mendapatkan orang yang tepat bagi suatu jabatan tertentu, sehingga orang tersebut mampu bekerja secara optimal dan dapat bertahan di perusahaan dalam waktu yang lama (Maharrani, Syukur, \& Catur, 2010). Meskipun tujuannya terdengar sangat sederhana, proses tersebut ternyata sangat kompleks, memakan waktu cukup lama dan biaya yang tidak sedikit dan sangat terbuka peluang untuk melakukan kesalahan dalam menentukan orang yang tepat (Tunggal \& Setiawan, 2015) (Wahyudi, 2016). Menentukan prasyarat untuk berbagai posisi dalam perusahaan dan melihat kemampuan khusus dari calon karyawan yang memenuhi prasyarat tertentu dalam pertemuan yang singkat adalah tugas dan tanggung jawab yang besar (Maharrani et al., 2010), karena itu dibutuhkan kejelian agar tidak terjadi salah pilih atau salah penempatan. Kesalahan dalam memilih orang yang tepat sangat besar dampaknya (Setiani, 2013) bagi perusahaan atau organisasi. Hal tersebut bukan saja karena proses rekrutmen dan seleksi itu sendiri telah menyita waktu (Widayu, Darma, Silalahi, \& Mesran, 2017), biaya dan tenaga, tetapi juga karena menerima orang yang salah untuk suatu jabatan akan berdampak pada efisiensi (Bellionardi \& Pujiart, 2013), produktivitas, dan dapat merusak moral kerja karyawan yang bersangkutan dan orang-orang di sekitarnya. Salah satu cara mengatasi masalah tersebut adalah adanya suatu metode yang dapat memberikan rekomendasi sebagai bahan pertimbangan untuk pengambilan keputusan secara tepat. Hal ini melatar belakangi penyeleksian calon karyawan dengan mengimplementasikan metode Analytical Hierarchy Process (AHP) (Handayani \& Muzakir, 2018).

Tujuan dari penelitian ini untuk memudahkan menentukan pelamar mana yang benar-benar berkompeten dan layak menjadi karyawan untuk posisi tertentu di sebuah perusahaan (misalnya posisi arsitek). Memudahkan penempatan karyawan pada divisi yang tersedia sesuai dengan keahlian yang dimiliki dan kebutuhan.

\section{METODE PENELITIAN}

\section{Jenis Penelitian}

Penelitian ini menggunakan pendekatan kuantitiatif dimana pengumpulan data dilakukan dengan menggunakan serangkaian instrumen penelitian berupa tes/kuesioner.

\section{Waktu dan Tempat Penelitian}

Tempat penelitian pada di PT Arkonin yang beralamat di Arkonin Building, 1st Floor, Jl. Bintaro Taman Timur, Bintaro Jaya, Jakarta 12330, Indonesia 12330 Jakarta.

\section{Target/Subjek Penelitian}

Target/subjek penelitian pada kriteriakriteria yang menjadi prioritas utama penerimaan karyawan diantaranya adalah pendidikan, pengalaman kerja, keterampilan khusus, etika, minat kerja dan kreatifitas.

\section{Data, Intrumen, dan Teknik Pengumpulan Data}

Tahap pengumpulan data adalah pengumpulan data dari tempat penelitian sesuai yang dibutuhkan.

a. Pengumpulan Data

Pengumpulan data yang dilakukan peneliti terbagi menjadi 2 cara. Cara pertama dengan observasi langsung, wawancara, dan kuesioner.

b. Populasi dan Sampel Penelitian

Saat ini memiliki 100 orang karyawan. Peneliti mengambil 3 orang sampel untuk dijadikan responden. 3 responden ini terdiri dari:

Tabel 1. Data Responden

\begin{tabular}{|c|c|c|}
\hline No & Jabatan & Jumlah \\
\hline 1 & $\begin{array}{l}\text { Kepala Divisi Umum, HRD, } \\
\text { Keuangan dan Legal }\end{array}$ & 1 \\
\hline 2 & Kepala Divisi Arsitektur & 1 \\
\hline 3 & Supervisor Arsitek & 1 \\
\hline & & 3 \\
\hline
\end{tabular}

\section{Teknik Analisis Data}

Analisa merupakan bagian penting dalam metodologi penelitian ilmiah, dikarenakan dengan melakukan analisis data tersebut dapat diberi arti dan makna yang berguna dalam suatu penyelesaian masalah. Metode Analytical Hierarchy Process (AHP) merupakan metode pengambilan keputusan yang komprehensif (Makkasau, 2013).

\section{HASIL PENELITIAN DAN PEMBAHASAN}

\section{A. Struktur Analytical Hierarchy Process}

Dalam Hierarchy keputusan ini terdapat objek yang akan dibahas atau goal, kriteria dan alternatif. Berikut ini adalah gambar dari struktur Hierarchy keputusan yang digunakan dalam penelitian ini: 


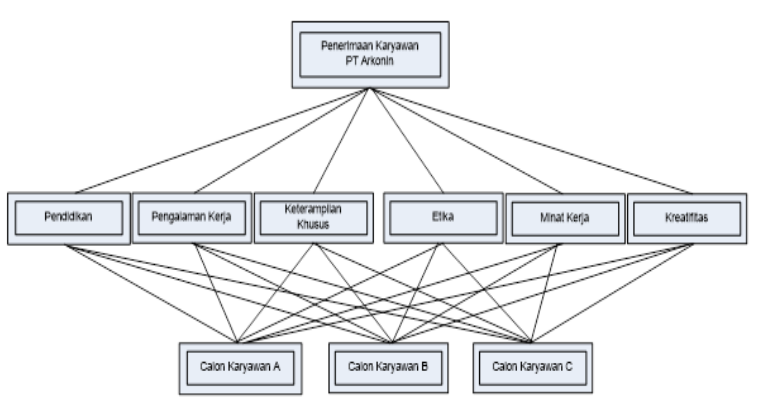

Gambar 1. Struktur Analytical Hierarchy Process Penerimaan Karyawan

Di dalam gambar 1 diatas terdapat 6 kriteria, berdasarkan wawancara yang dilakukan langsung dengan bagian penerimaan karyawan, berikut merupakan penjelasan masing-masing kriteria tersebut:

1. Pendidikan, adalah kriteria utama untuk menjabat suatu posisi. Misalnya untuk posisi arsitek, seorang calon karyawan harus memiliki latar belakang pendidikan dari jurusan teknik arsitektur.

2. Pengalaman kerja, merupakan salah satu kriteria terpenting dalam penerimaan karyawan. Meskipun calon karyawan tersebut baru menyelesaikan pendidikan pada salah satu perguruan tinggi, namun pengalaman kerja atau pengalaman praktek kerja yang pernah dilakukan sebelumnya akan menjadi pertimbangan penting dalam penilaian penerimaan karyawan terkait dengan seberapa banyak proyek yang pernah ditangani untuk seorang arsitek.

3. Keterampilan khusus, merupakan kriteria yang cukup penting dalam penerimaan karyawan khususnya untuk posisi arsitek. Seorang arsitek wajib memiliki keterampilan khusus misalnya dapat mengoperasikan program AutoCAD, 3DS Max, Sketch UP dan lain-lain.

4. Etika, merupakan kriteria yang tidak kalah penting dalam penerimaan karyawan. Hal ini berkaitan dengan cara berinteraksi dengan karyawan pihak internal maupun eksternal perusahaan.

5. Minat kerja, adalah seberapa besar ketertarikan calon karyawan terhadap perusahaan dan posisi yang ditawarkan dengan kemampuan calon karyawan tersebut.

6. Kreatifitas, merupakan kriteria yang penting dalam penerimaan karyawan. Kreatifitas yang tinggi harus dimiliki seorang arsitek untuk mengembangkan ide-ide baru dalam pemenuhan kebutuhan customer.

\section{B. Hasil Pengolahan Data Analytical Hierarchy Process}

\section{Penentuan Bobot Antar Kriteria}

Setelah hasil kuesioner dari setiap responden di input menggunakan expert choice 2000, kemudian hasil kuesioner setiap responden harus dijadikan satu kesatuan sehingga menghasilkan hasil akhir. Berikut ini adalah hasil akhir dari pengolahan data kuesioner.

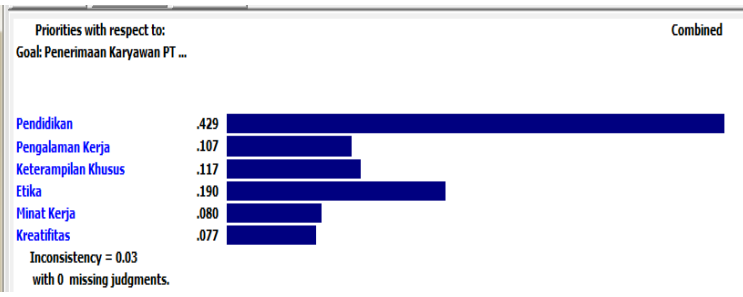

Gambar 2. Nilai Bobot Prioritas Kriteria

Berdasarkan Penerimaan Karyawan (Combined)

Berdasarakan hasil pengolahan data responden ahli diperoleh bahwa utama atau tertinggi yaitu kriteria pendidikan dengan nilai bobot 0,429 atau sebanding dengan 42,9\% dari total kriteria. Peringkat prioritas kedua kriteria berikutnya adalah etika dengan nilai bobot 0,190 atau sebanding dengan nilai bobot $19 \%$ dari total kriteria. Peringkat prioritas ketiga kriteria berikutnya adalah keterampilan khusus dengan nilai bobot 0,117 atau sebanding dengan 11,7\% dari total kriteria. Peringkat prioritas keempat kriteria berikutnya adalah pengalaman kerja dengan nilai bobot 0,107 atau sebanding dengan $10,7 \%$ dari total kriteria. Peringkat prioritas kelima kriteria berikutnya adalah minat kerja dengan nilai bobot 0,080 atau sebanding dengan 8\% dari total kriteria. Peringkat prioritas yang terakhir adalah kreatifitas dengan nilai bobot 0,077 atau sebanding dengan $7,7 \%$ dari total kriteria.

\section{Penentuan Bobot Antar Alternatif Berdasarkan Kriteria \\ a. Penentuan Bobot Antar Alternatif Berdasarkan Kriteria Pendidikan}

Berdasarkan hasil pengolahan data responden ahli diperoleh bahwa prioritas utama atau tertinggi yaitu alternatif Calon Karyawan B dengan nilai bobot 0,487 atau sebanding dengan $48,7 \%$ dari total alternatif. Peringkat prioritas kedua adalah Calon Karyawan A dengan nilai bobot 0,425 atau sebanding dengan 42,5\% dari total alternative. Peringkat prioritas yang terakhir adalah Calon Karyawan C dengan nilai bobot 0,088 atau sebanding dengan $8,8 \%$ dari total alternatif. 


\section{b. Penentuan Bobot Antar Alternatif Berdasarkan Kriteria Pengalaman Kerja}

Berdasarkan hasil pengolahan data responden ahli diperoleh bahwa prioritas utama atau tertinggi yaitu alternatif Calon Karyawan B dengan nilai bobot 0,705 atau sebanding dengan $70,5 \%$ dari total alternatif. Peringkat prioritas kedua adalah Calon Karyawan A dengan nilai bobot 0,211 atau sebanding dengan 21,1\% dari total alternative. Peringkat prioritas yang terakhir adalah Calon Karyawan C dengan nilai bobot 0,084 atau sebanding dengan $8,4 \%$ dari total alternatif.

\section{c. Penentuan Bobot Antar Alternatif Berdasarkan Kriteria Keterampilan Khusus}

Berdasarkan hasil pengolahan data responden ahli diperoleh bahwa prioritas utama atau tertinggi yaitu alternatif Calon Karyawan B dengan nilai bobot 0,518 atau sebanding dengan 51,8\% dari total alternatif. Peringkat prioritas kedua adalah Calon Karyawan A dengan nilai bobot 0,396 atau sebanding dengan $39,6 \%$ dari total alternative. Peringkat prioritas yang terakhir adalah Calon Karyawan C dengan nilai bobot 0,087 atau sebanding dengan $8,7 \%$ dari total alternatif.

\section{d. Penentuan Bobot Antar Alternatif Berdasarkan Kriteria Etika \\ Berdasarkan hasil pengolahan data responden} ahli diperoleh bahwa prioritas utama atau tertinggi yaitu alternatif Calon Karyawan A dengan nilai bobot 0,470 atau sebanding dengan $47 \%$ dari total alternatif. Peringkat prioritas kedua adalah Calon Karyawan B dengan nilai bobot 0,435 atau sebanding dengan 43,5\% dari total alternative. Peringkat prioritas yang terakhir adalah Calon Karyawan C dengan nilai bobot 0,095 atau sebanding dengan 9,5\% dari total alternatif.

\section{e. Penentuan Bobot Antar Alternatif Berdasarkan Kriteria Minat Kerja}

Berdasarkan hasil pengolahan data responden ahli diperoleh bahwa prioritas utama atau tertinggi yaitu alternatif Calon Karyawan B dengan nilai bobot 0,414 atau sebanding dengan $41,4 \%$ dari total alternatif. Peringkat prioritas kedua adalah Calon Karyawan A dengan nilai bobot 0,350 atau sebanding dengan 35\% dari total alternative. Peringkat prioritas yang terakhir adalah Calon Karyawan C dengan nilai bobot 0,235 atau sebanding dengan 23,5\% dari total alternatif.

\section{f. Penentuan Bobot Antar Alternatif Berdasarkan Kriteria Kreatifitas \\ Berdasarkan hasil pengolahan data responden} ahli diperoleh bahwa prioritas utama atau tertinggi yaitu alternatif Calon Karyawan A dengan nilai bobot 0,451 atau sebanding dengan $45,1 \%$ dari total alternatif. Peringkat prioritas kedua adalah Calon Karyawan B dengan nilai bobot 0,373 atau sebanding dengan $37,3 \%$ dari total alternative. Peringkat prioritas yang terakhir adalah Calon Karyawan C dengan nilai bobot 0,176 atau sebanding dengan 17,6\% dari total alternatif.

\section{Perhitungan Hasil Pengolahan Data Analytical Hierarchy Process \\ Setelah mendapatkan nilai masing-masing dari} setiap pembobotan kriteria dan setiap alternatif berdasarkan kriteria. Langkah terakhir yang harus dilakukan untuk penerimaan karyawan adalah menghitung nilai aggregate masing-masing calon karyawan yang dijadikan alternatif. Nilai aggregate diperoleh dengan cara mengalikan nilai bobot setiap kriteria dengan nilai bobot setiap alternatif calon karyawan dengan kriteria yang sama.

Tabel 2. Tabel Hasil Penilaian Akhir

\begin{tabular}{|c|c|c|c|c|}
\hline Alternatif & Kriteria & Bobot Kriteria & Bobot Alternatif & Aggregate/prty \\
\hline \multirow{6}{*}{ Calon Karyawan A } & Pendidikan & 0.419 & 0.425 & 0.17825 \\
\hline & Pengalaman Kerja & 0.111 & 0.224 & 0.02488 \\
\hline & Keterampilan Khusus & 0.118 & 0.396 & 0.04686 \\
\hline & Etika & 0.192 & 0.470 & 0.09002 \\
\hline & Minat Kerja & 0.081 & 0.350 & 0.02847 \\
\hline & Kreatifitas & 0.079 & 0.451 & 0.03549 \\
\hline \multirow{5}{*}{ Calon Karyawan B } & Pendidikan & 0.419 & 0.486 & 0.20390 \\
\hline & Pengalaman Kerja & 0.111 & 0.677 & 0.07516 \\
\hline & Keterampilan Khusus & 0.118 & 0.517 & 0.06126 \\
\hline & Etika & 0.192 & 0.435 & 0.08327 \\
\hline & Minat Kerja & 0.081 & 0.413 & 0.03357 \\
\hline \multirow{7}{*}{ Calon Karyawan C } & Kreatifitas & 0.079 & 0.373 & 0.02930 \\
\hline & Pendidikan & 0.419 & 0.088 & 0.03699 \\
\hline & Pengalaman Kerja & 0.111 & 0.099 & 0.01095 \\
\hline & Keterampilan Khusus & 0.118 & 0.087 & 0.01028 \\
\hline & Etika & 0.192 & 0.095 & 0.01827 \\
\hline & Minat Kerja & 0.081 & 0.236 & 0.01921 \\
\hline & Kreatifitas & 0.079 & 0.176 & 0.01385 \\
\hline
\end{tabular}


Berdasarkan hasil perhitungan Aggregate menggunakan rumus yang telah di hitung dan mendapatkan hasil rata-rata yang mendekati, dapat dilihat tampilan di Expert Choice 2000 pada gambar 3 dibawah ini:

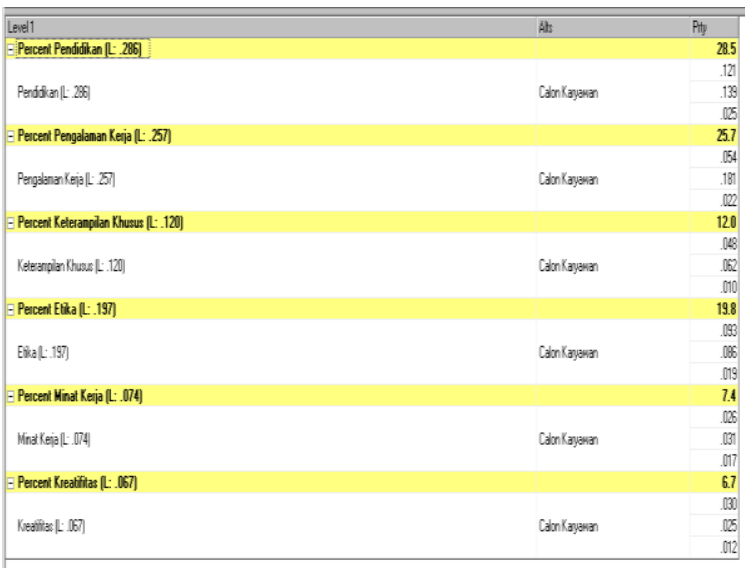

Gambar 3. Hasil Penilaian Akhir AHP

\section{Pembahasan dari Hasil Pengolahan Data Analytical Hierarchy Process}

Setelah pengolahan dan perhitungan data selesai dilakukan, kemudian diperoleh hasil seperti gambar 10 seperti dibawah ini.

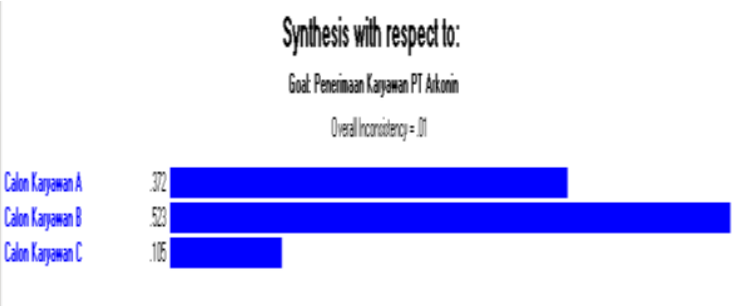

Gambar 4. Synthesis with respect untuk penerimaan karyawan

Gambar 4, merupakan hasil dari perhitungan keseluruhan Analytical Hierachy Process untuk penerimaan karyawan dengan menggunakan aplikasi Expert Choice 2000 dalam bentuk grafik. Hasil penjumlahan ini merupakan hasil akhir dari penerimaan karyawan. Calon Karyawan A dengan nilai bobot 37,2\%, Calon Karyawan B dengan nilai bobot 52,3\% sedangkan Calon Karyawan C dengan nilai bobot $10,5 \%$.

\section{Inconsistency Ratio (CR)}

Inconsistency ratio atau rasio inkonsistensi data responden ahli merupakan parameter yang digunakan untuk memeriksa apakah perbandingan berpasangan telah dilakukan dengan konsekuen atau tidak. Rasio inkonsistensi data dianggap baik jika nilai CR-nya $\leq 0,1$. Untuk mengecek rasio inkonsistensi data responden, berikut ini ditampilkan nilai inkonsistensi pada masing-masing perbandingan.

Tabel 3. Tabel Perbandingan Elemen dan Nilai CR

\begin{tabular}{clc}
\hline No. & \multicolumn{1}{c}{ Matriks Perbandingan Elemen } & Nilai CR \\
\hline 1. & $\begin{array}{l}\text { Perbandingan elemen antar kriteria } \\
\text { berdasarkan penerimaan karyawan }\end{array}$ & 0,03 \\
2. & $\begin{array}{l}\text { Perbandingan elemen kriteria Pendidikan } \\
\text { Perbandingan elemen kriteria Pengalaman }\end{array}$ & 0,00 \\
3. & $\begin{array}{l}\text { Kerja } \\
\text { Perbandingan elemen kriteria Keterampilan }\end{array}$ & 0,03 \\
4. & Khusus & 0,01 \\
5. & Perbandingan elemen kriteria Etika & 0,00 \\
6. & Perbandingan elemen kriteria Minat Kerja & 0,04 \\
7. & Perbandingan elemen kriteria Kreatifitas & 0,00 \\
\hline
\end{tabular}

Dapat disimpulkan bahwa perbandingan berpasangan yang diberikan responden ahli memiliki nilai rasio inkonsistensi yang lebih kecil dari 0,1 sebagai batas maksimum nilai rasio inkonsistensi. Dengan demikian hasil perhitungan dari data responden cukup konsisten.

\section{SIMPULAN DAN SARAN}

\section{Simpulan}

Proses penerimaan karyawan dengan menggunakan metode Analytical Hierarchy Process (AHP) di software Expert Choice 2000 dapat memudahkan bagian rekrutmen untuk membuat keputusan terkait penerimaan karyawan sesuai kriteria yang telah ditentukan. Berdasarkan perhitungan Analytical Hierarchy Process, diperoleh prioritas kriteria yang paling penting dalam proses penerimaan karyawan dimana pendidikan, pengalaman kerja, etika, keterampilan khusus, minat kerja dan kreatifitas menjadi prioritas dalam membuat keputusan penerimaan karyawan. Hasil analisis perhitungan Analytical Hierarchy Process menyatakan bahwa alternatif calon karyawan yang terpilih dan yang paling sesuai dengan kriteria yang ditentukan adalah calon karyawan B atas nama Annisa. Data hasil AHP yang diperoleh dari kuesioner dengan 3 responden yang memberikan jawabannya dihitung dan didapat hasil akhir bahwa calon karyawan B unggul $(52,3 \%)$ berbanding dengan calon karyawan A $(37,2 \%)$ dan calon karyawan C $(10,5 \%)$.

\section{Saran}

Dilihat dari aspek manajerial studi penelitian dapat diterapkan di setiap perusahaan. Penelitian yang dilakukan ini berhubungan dengan keperluan sebuah perusahaan dalam memenuhi kebutuuhan tenaga kerja, sehingga untuk waktu, kondisi dan tempat yang berbeda perlu dilakukan penelitian 
lanjutan. Dilihat dari aspek sistem konsistensi perlu diperhatikan pada pairwaise comparisons (perbandingan berpasangan) agar tidak terjadi inkonsistensi dengan cara mengukur instrument pertanyaan yang akan diajukan dalam kuesioner. Konsistensi combined juga perlu diperhatikan karena terkadang 3 ahli atau responden memiliki hasil pemikiran yang berbeda yang dapat menyebakan pairwise comparisons combined menjadi inkonsistensi. Dilihat dari aspek penelitian penulis memberikan saran agar aplikasi dapat dikembangkan dengan metode lain seperti neuro-fuzzy, simple additive weighting atau metode yang lain yang biasa digunakan untuk pengambilan keputusan multi kriteria.

\section{DAFTAR REFERENSI}

Bellionardi, A. R. K., \& Pujiart, E. S. (2013). Model Analisis Perekrutan Dan Seleksi Karyawan Di PT. Semarang Autocomp Manufacturing Indonesia (SAMI). Jurnal Ilmiah Dinamika Ekonomi Dan Bisnis, 1(1), 42-55. Retrieved from

http://jurnal.untagsmg.ac.id/index.php/jide b/article/view/253

Frieyadie, F. (2017). Penerapan Metode AHP Sebagai Pendukung Keputusan Penetapan Beasiswa. 14Jurnal Pilar Nusa Mandiri, 13(1), 49-58. Retrieved from http://ejournal.nusamandiri.ac.id/index.php /pilar/article/view/146

Hadi, A. F., Purnama, P. A. W., \& Rahman, S. N. (2018). Pembangunan Aplikasi Multimedia Sebagai Media Analisa Kesiapan Kerja Lulusan Perguruan Tinggi Pada Sektor Perbankan Syariah. In Seminar Nasional Teknologi Informasi, Komunikasi dan Industri (SNTIKI-10) (pp. 27-34). Kota Pekanbaru: Fakultas Sains dan Teknologi UIN Sultan Syarif Kasim Riau. Retrieved from http://ejournal.uin-

suska.ac.id/index.php/SNTIKI/article/view/ 5849

Handayani, R. I., \& Muzakir, A. (2018). SISTEM PENDUKUNG KEPUTUSAN PENERIMAAN KARYAWAN DENGAN MENGGUNAKAN METODE ANALYTICAL HIERARCHY PROCESS (AHP) STUDI KASUS: PT. VIRTUS VENTURAMA. Jurnal Pilar Nusa Mandiri, 14(1), 43-48. Retrieved from http://ejournal.nusamandiri.ac.id/index.php /pilar/article/view/87
Herdiyanti, A., \& Widianti, U. D. (2013). PEMBANGUNAN SISTEM PENDUKUNG KEPUTUSAN REKRUTMEN PEGAWAI BARU DI PT. ABC. Jurnal Ilmiah Komputer Dan Informatika (KOMPUTA), 2(2), 63-70. Retrieved from https://search.unikom.ac.id/index.php/kom puta/article/view/91

Maharrani, R. H., Syukur, A., \& Catur, P. T. (2010). Penerapan Metode Analytical Hierarchi Process Dalam Penerimaan Karyawan Pada PT. Pasir Besi Indonesia. Jurnal Teknologi Informasi, 6(1), 102-114.

Makkasau, K. (2013). PENGGUNAAN METODE ANALYTIC HIERARCHY PROCESS (AHP) DALAM PENENTUAN PRIORITAS PROGRAM KESEHATAN (STUDI KASUS PROGRAM PROMOSI KESEHATAN). J@TI UNDIP : JURNAL TEKNIK INDUSTRI, 7(2), 105-112. https://doi.org/10.12777/jati.7.2.105-112

Setiani, B. (2013). KAJIAN SUMBER DAYA MANUSIA DALAM PROSES REKRUTMEN TENAGA KERJA DI PERUSAHAAN. Jurnal Ilmiah Widya, 1(1), 38-44. Retrieved from http://e-

journal.jurwidyakop3.com/index.php/jurnalilmiah/article/view/106

Tunggal, A. C., \& Setiawan, R. (2015). Studi Deskriptif Rekrutmen dan Seleksi pada PT. Multi Artistikacithra. AGORA, 3(1), 647-650. Retrieved from http://publication.petra.ac.id/index.php/ma najemen-bisnis/article/view/2923

Wahyudi, A. D. (2016). SISTEM PENDUKUNG KEPUTUSAN SELEKSI PENERIMAAN STAFF ADMINISTRASI MENGGUNAKAN METODE PROFILE MATCHING. Jurnal TEKNOINFO, 10(2), 1-4. https://doi.org/https://doi.org/10.33365/jti .v10i2.13

Widayu, H., Darma, S., Silalahi, N., \& Mesran. (2017). Data Mining Untuk Memprediksi Jenis Transaksi Nasabah Pada Koperasi Simpan Pinjam Dengan Algoritma C4.5. Issn 2548-8368, Vol 1, No(June), 7. 